\title{
Assessment of Health promoting life styles of nursing students at Assiut University
}

\author{
Walaa H. Abd al-fatah, Kawthar A. Fadel, Soad A. Sharkawy.
}

Assistant Lecturer of Community Health Nursing, Faculty of Nursing, Assiut University, Egypt.

Professor of public health and Community Medicine, Faculty of Medicine, Assiut University, Egypt.

Assistant Professor of Community Health Nursing, Faculty of Nursing, Assiut University, Egypt.

\begin{abstract}
Health promoting behaviors and psychosocial well being are important determinants of health status and quality of life. Aim of the study: Assess the health promoting lifestyle of nursing student's at Assuit University. Methods Across-sectional descriptive research design carried out in Assiut University included 1045 students from faculty of nursing (430 students), technical institute of nursing (323 students) and secondary nursing school (292 students). Tools: Data collected by using two tools; tool (1): interview form consisted of two parts; first part included sociodemographic data. The second part included assessment of anthropometric measurement was used to record weight and height measurements for all students then calculate BMI. Tool (2): Health Promoting Life Style Profile (HPLP) scale, the scale consists of 48 items. Result: $39.1 \%$ of the studied students were their age more than 17years. The mean score of health promoting life style among studied students is higher in self-actualization and health (38.12 \pm 7.46 and $25.07 \pm 6.51)$ respectively. Conclusion: The mean score of health promoting life style among studied students is higher in self-actualization and health $(38.12 \pm 7.46$ and $25.07 \pm 6.51)$ respectively. Recommendation: Increasing Health education programs for students about how to maintain health promote and achieve maximum level of well-being and avoid risky behaviors.
\end{abstract}

Key words: Health Promoting life style, Nursing Students \& Assiut University.

\section{Introduction}

The new paradigm of health indicates that health is the responsibility of all individuals and societies, since the determinants of health do not depend on medical and public health services but on several factors, including personal and environmental factors. Adolescents are a large and growing segment of the world's population. More than half of the world's population is below the age of 25 , and one in every two young people in the world is adolescent (Wittayapun et al., 2013 \& Lawan et al., 2010). Nowadays, health promotion is increasingly paid more attention and one of the main challenges of countries is providing health care according to the health promotion approaches. So that people could be capable to be responsible for their own health and follow healthy life style. This practice should be started from childhood and adolescence and keep individuals safe against major health risk during their life. Life style plays an important role in biopsychological health. There is an interlock relationship between health problems and life style (Golmakani et al., 2013).

There are sound public health, economic and human rights reasons for investing in the health and development of adolescents. Investing in the health of adolescents improve the health and well-being of many millions of adolescents who experience health problems such as depression, anemia or infection; and promote the adoption of healthy behaviors' that help prevent health problems that occur later in life, such as cardiovascular diseases and lung cancer resulting from physical inactivity and tobacco use initiated during adolescence (WHO, 2009).

Lifestyle is routine and usual activities' that people have accepted them. While these activities' effect on people's healthy on serving suitable diet, sleeping and exercising, controlling weight, not smoking and alcohol using and security against illnesses that all these make lifestyle Promotion is necessary for health (Omedi, et al., 2013) .

A health-promoting lifestyle has been defined as a 'multidimensional pattern of self-initiated actions and perceptions that serve to maintain or enhance the level of wellness, self-actualization, and fulfillment of the individual' 'This trend toward health and health promotion is directed toward increasing individual responsibility for health; however, knowledge of health-promoting behaviors is essential. The World Health Organization's objective "Health for All is intended to apply to all nations and cultures. One of the strategies suggested to meet this goal is to improve education and training programs in health promotion and prevention for health professionals and nursing students

(Omedi, et al., 2013).

Nurses are often expected as role models and as leaders to activate communities for health promotion. Nurses have the potential to influence clients' 
behaviors. Nurse's as role modeling healthy lifestyles encourage clients to do the same. In other words, nurses can not meet the clients' needs unless they pay much attention to their own health-promoting lifestyles. It may be even more important that the nurses themselves have a healthy lifestyle, thus serving as role models for patients (Wittayapun et al., 2013).

\section{Significance of the study}

It has become increasingly evidence that lifestyle patterns and health risk factors are associated with the major causes of morbidity and mortality. Healthpromoting activities and a healthy lifestyle should be regarded as a major strategy to facilitate and preserve health. There aren't enough researches studying the life styles of the nursing students, so the present study aims to assess and evaluate the current life styles of nursing students.

\section{Aim of the study}

- Assess health promoting life styles of nursing students.

\section{Study questions}

- Is there relation ship between socio demographic and health promoting life styles of nursing students?

Methods

\section{Study design}

A cross - sectional descriptive research was utilized in this study.

\section{Study settings}

The study was conducted in secondary nursing school, technical institute of nursing and faculty of nursing at Assiut University.

\section{Study subjects}

The total number of students (2343) from this number (1045) who accept to share in the study from Faculty of nursing 430 student from first grade 53 student, second grade 50 student, third grade 155 student, fourth grade 172 student, Technical institute of nursing 323 student from first grade 285 student, second grade 38 student and Secondary nursing school 292 student from first grade 50 student, second grade 30 student, third grade 110 student, fourth grade 102 student).

Sample

Convenient sample was adopted in this study.

Tools

Tool I: Structure questionnaire sheet was designed and developed by the researcher after reviewing of different researches and pertinent literature. It includes two parts.
Part I: Socio demographic characteristic for students such as (gender, age, grade, social class, mother \& father education \& occupation ,qualification according to Abd Altwab scale (2004).

Part II: Anthropometric measurement was used to record weight and height to calculate BMI.

The BMI : is defined as the body mass divided by the square of the body height, and is universally expressed in units of $\mathrm{kg} / \mathrm{m}^{2}$, resulting from weight in kilograms and height in meters. If pounds and inches are used, a conversion factor of $703(\mathrm{~kg} / \mathrm{m} 2) /(\mathrm{lb} / \mathrm{in} 2)$ must be applied. When the term BMI is used informally, the units are usually omitted (WHO, 2013).

$$
\mathrm{BMI}=\frac{\text { mass }_{\mathrm{kg}}}{\text { height }_{\mathrm{m}}^{2}}=\frac{\text { mass }_{\mathrm{lb}}}{\text { height }_{\text {in }}^{2}} \times 703
$$

Tool II

The health Promoting Life Style profile (HPLP) scale adapted from Pender, (1996). It provides information to develop an individualized health promotion plan that identifies lifestyle strengths and resources as well as areas for further growth. The scale consists of 48 items measuring six dimensions: self-actualization (13 items), health responsibilities (10 items), exercise (5 items), nutrition (6 items), interpersonal support (7 items), and stress management ( 7 items). The response to items is on a four-point Likert scale from never (1) to routinely (4). The total of each subscale is scored separately by summing up the responses.

The total score ranges from 48 to 192 , with higher scores indicating more frequently performing health promoting behaviors The Alpha coefficient reliability of the scale was 0.92 and alpha coefficient reliability of the subscales varied from 0.70 to 0.90 the researcher will using Arabic scale which translated by (Ali et al., 2012).

The first subscale

Included (6 items) covering nutrition which include Eat breakfast, Read labels to identify nutrients before you eat, Eat 3 meals in day regularly, Choose a diet without protecting substance, Eat of fiber, bread, cereal, rice vegetables, fruit each day, Choose a diet contain of protein, fat, carbohydrates, minerals.

The second subscale

Included (5 items ) reflecting exercise which included Exercise walking (Light Sport) three times a week at least, Take part in light to moderate physical activity (such as sustained walking 20-30 minutes three or more times a week, Follow a planned exercise program, Get exercise during usual daily activities (such as walking during lunch, using stairs instead of elevators, parking car away from destination and walking, Take part in leisure-time (recreational) 
physical activities (such as swimming, dancing, bicycling).

\section{The third subscale}

Included (10 items ) reflecting health responsibilities which included Report any unusual signs or symptoms to a physician or other health professional, Question health professionals in order to understand their instructions, Read books and magazines that deal with the health aspects,

Ask your doctor again when treatment recommendations unclear, Discuss my health concerns with health professionals, Measure your blood pressure to see how much reassurance, watch TV programs about improving your environment, Ask for information from health professionals about how to take good care of myself, Inspect my body at least monthly for physical changes/danger signs, Attend educational programs on personal health care.

\section{The Fourth subscale}

Included (7 items ) reflecting Stress management which included Take some time for relaxation each day, Feel content and at peace with myself ,know reasons of stress in your life, Practice relaxation or meditation for 15-20 minutes daily, do relaxation technique before bedtime, Concentrate on pleasant thoughts at bedtime ,Using means such as recreational club to visit relatives and watching television to ease the sense of sadness and distress.

\section{The fifth subscale}

Included (7 items) reflecting Inter personal support which included discuss my problems and concerns with people close to me, Praise other people easily for their achievements, Touch and am touched by people I care about, Maintain meaningful and fulfilling relationships with others, Spend time with close friends, Find it easy to show concern, love and warmth to others, Express your love and affection for people who care about them.

\section{The six subscale}

Included (7 items)covering Self actualization which included feel satisfaction about your self, feel I am growing and changing in positive ways indifferent educational level, feel happiness and satisfaction, know power and weakness points in my life, Work toward long-term goals in my life, Look forward to the future, I Am aware of what is important to me in life, respect all of works achievement in your life, Find each day interesting and challenging, find your environment happy and agreeable, express your feeling in positive way, you are fait in determent your goals and Believe that my life has purpose.

\section{Methodology}

\section{Administrative Phase}

An official approval letter was obtained from the Dean of the Faculty of Nursing, Assuit University to vice for student's affairs at Faculty of Nursing and director of nursing school and technical institute of nursing this letter include a permission to carry out the study.

\section{Pilot study}

Pilot study was carried out before starting of data collection on $10 \%$ students who were excluded from the sample. The aim of pilot study is to test the clarity of the tools and to estimate the time required to fill the questionnaire. Based on the results of pilot study, the necessary modification in the sheet was done.

\section{Ethical considerations}

The researcher explained the purpose and nature of the study for each student .The student has the right to agree or disagree to participate in the study; consent to participate in the study was secured orally from every student and informed that the obtained information will be confidential and will be used only for the purpose of the study.

Field work

- The researcher began to collect data from first of February 2014 to the end of August 2014 for (1045) students who accept to participate in this study. The researcher met the students in their classes and explains the structure questionnaire sheet in the beginning for all students and it was filled by students themselves in every grade.

- The researcher took height by using measuring tap, explained the procedures to the students, Remove the student's shoes and socks, Lets the students stands as tall and straight as possible with the head in the midline and the line of vision parallel to the floor, any bending of knees, slumping of the shoulders and rising of heal of the feet is checked and corrected. the student's back should be to the wall or another vertical surface, Let the student's heels, buttocks and back of the shoulder touch the wall or the vertical surface, place thick book on the top of the head, the side of the book must rest firmly against the wall to form a right angle, read the result to the nearest centimeter, record the finding.

- Measure weight by using balanced scale, explain the procedures to the student, place the scale horizontally on a firm surface, check to see that scale is balanced by setting it at zero, Remove the student's heavy clothing (jacket), remove the student 's shoes, Let's student stand vertical line above scale, read the scale measure and record the weight Each grade took about (20-30) minutes. The data was collected on average one or two day / week with the average number of 20-40 students / day. 
Results

Table (1): Distribution of the studied students regarding to thier socio demographic characteristics, qualification and BMI at Assuit University, 2014 ( $n=1045)$.

\begin{tabular}{|c|c|c|}
\hline Items & No. $(n=1045)$ & $\%$ \\
\hline \multicolumn{3}{|l|}{ Age } \\
\hline $15-$ & 244 & 23.3 \\
\hline $17-$ & 409 & 39.1 \\
\hline$>20$ years & 392 & 37.5 \\
\hline Mean \pm SD (Range) & \multicolumn{2}{|c|}{$19.61 \pm 1.87(15.0-23.0)$} \\
\hline \multicolumn{3}{|l|}{ Sex } \\
\hline Male & 68 & 6.5 \\
\hline Female & 977 & 93.5 \\
\hline \multicolumn{3}{|l|}{ Housing } \\
\hline Family house & 734 & 70.2 \\
\hline University Dormitories & 172 & 16.5 \\
\hline External housing & 139 & 13.3 \\
\hline \multicolumn{3}{|l|}{ Mother education } \\
\hline Illiterate & 384 & 36.7 \\
\hline Read \& write & 95 & 9.1 \\
\hline Basic & 201 & 19.2 \\
\hline Secondary & 260 & 24.9 \\
\hline University & 78 & 7.5 \\
\hline Postgraduate & 27 & 2.6 \\
\hline \multicolumn{3}{|l|}{ Father education } \\
\hline Illiterate & 153 & 14.6 \\
\hline Read \& write & 95 & 9.1 \\
\hline Basic & 257 & 24.6 \\
\hline Secondary & 335 & 32.1 \\
\hline University & 158 & 15.1 \\
\hline Postgraduate & 47 & 4.5 \\
\hline \multicolumn{3}{|l|}{ Father occupation } \\
\hline Employee & 468 & 44.8 \\
\hline Farmer & 143 & 13.7 \\
\hline Free business & 66 & 6.3 \\
\hline Skilled & 96 & 9.2 \\
\hline Unskilled & 96 & 9.2 \\
\hline Retired & 81 & 7.8 \\
\hline No work & 20 & 1.9 \\
\hline Died & 75 & 7.1 \\
\hline \multicolumn{3}{|l|}{ Mother occupation } \\
\hline Working & 150 & 14.3 \\
\hline Housewife & 885 & 84.7 \\
\hline Died & 10 & 1.0 \\
\hline \multicolumn{3}{|l|}{ Qualification } \\
\hline Faculty of Nursing & 430 & 41.1 \\
\hline Institute of Nursing & 323 & 30.9 \\
\hline School of Nursing & 292 & 27.9 \\
\hline \multicolumn{3}{|l|}{ Grades: } \\
\hline First & 388 & 37.1 \\
\hline Second & 118 & 11.3 \\
\hline Third & 265 & 25.4 \\
\hline Fourth & 274 & 26.2 \\
\hline
\end{tabular}




\begin{tabular}{|l|c|c|}
\hline \multicolumn{1}{|c|}{ Items } & \multicolumn{1}{|c|}{ No. (n= 1045) } \\
\hline \hline BMI & 90 & 8.6 \\
\hline Underweight(18.5 and below) & 691 & 66.1 \\
\hline $\begin{array}{l}\text { Normal(From 18.5 to 25.0 (Standard } \\
\text { weight is 22) }\end{array}$ & 211 & 20.2 \\
\hline Overweight(From 25.0 to 30.0) & 53 & 5.1 \\
\hline Obese( from 30.0 to 40.0 and above) & & \\
\hline
\end{tabular}

Table (2): Distribution of the Studied students regarding to their score of health promoting life style, at Assuit University, 2014(n= 1045).

\begin{tabular}{|l|c|c|c|}
\hline \multicolumn{1}{|c|}{ Items } & Score & Mean \pm SD & Range \\
\hline Nutrition & 24 & $15.89 \pm 3.45$ & $6-24$ \\
\hline Sports & 20 & $11.56 \pm 3.59$ & $5-20$ \\
\hline Health & 40 & $25.07 \pm 6.51$ & $10-40$ \\
\hline Stress management & 28 & $20.18 \pm 4.20$ & $7-28$ \\
\hline Interpersonal support & 28 & $22.51 \pm 4.12$ & $7-28$ \\
\hline Self-actualization & 52 & $38.12 \pm 7.46$ & $13-52$ \\
\hline
\end{tabular}

Table (3): Distribution of the studied students regarding to correlations between their HPL with their age and their BMI at Assuit university (2014).

\begin{tabular}{|l|c|c|c|c|}
\hline \multirow{2}{*}{ Items of HPL } & \multicolumn{2}{c|}{ Age } & \multicolumn{2}{c|}{ BMI } \\
\cline { 2 - 5 } & r-value & P-value & r-value & 0.192 \\
\hline Nutrition & -0.120 & $0.000^{*}$ & -0.040 & $0.001^{*}$ \\
\hline Sports & -0.062 & $0.046^{*}$ & -0.098 & 0.368 \\
\hline Health & -0.083 & $0.007^{*}$ & -0.028 & 0.355 \\
\hline Stress-management & -0.110 & $0.00 *^{*}$ & -0.029 & 0.578 \\
\hline Inter-personal support & -0.070 & $0.024^{*}$ & -0.017 & $0.023^{*}$ \\
\hline Self-actualization & -0.128 & $0.000^{*}$ & -0.070 & $0.039^{*}$ \\
\hline Health Promoting Lifestyles & -0.133 & $0.000^{*}$ & -0.064 & \\
\hline
\end{tabular}

*There is statistical significance difference Pearson correlation

Table (4): Relation ship between health promoting life style of studied students and their age at Assuit university (2014).

\begin{tabular}{|l|c|c|c|c|}
\hline \multirow{2}{*}{\multicolumn{1}{c|}{ Items of HPL }} & \multicolumn{3}{c|}{ Age (years) } & \multirow{2}{*}{ P-value } \\
\cline { 2 - 5 } & $\mathbf{1 5}-$ & $\mathbf{1 7}-$ & > 20 & \\
\cline { 2 - 5 } & Mean \pm SD & Mean \pm SD & Mean \pm SD & \\
\hline Nutrition & $16.40 \pm 3.69$ & $15.81 \pm 3.14$ & $15.66 \pm 3.58$ & $0.027^{*}$ \\
\hline Sports & $11.57 \pm 4.04$ & $11.79 \pm 3.41$ & $11.32 \pm 3.48$ & 0.183 \\
\hline Health & $25.82 \pm 7.09$ & $24.84 \pm 6.10$ & $24.83 \pm 6.54$ & 0.121 \\
\hline Stress-management & $20.65 \pm 4.45$ & $20.32 \pm 4.06$ & $19.74 \pm 4.14$ & $0.020^{*}$ \\
\hline Inter-personal support & $22.84 \pm 4.12$ & $22.57 \pm 3.89$ & $22.25 \pm 4.33$ & 0.200 \\
\hline Self-actualization & $39.52 \pm 7.75$ & $37.71 \pm 7.28$ & $37.67 \pm 7.38$ & $0.004^{*}$ \\
\hline Health Promoting Lifestyles & $136.80 \pm 24.04$ & $133.04 \pm 20.30$ & $131.48 \pm 21.53$ & $0.010^{*}$ \\
\hline
\end{tabular}

* There is statistical significance difference ANOVA test 
Table (5): Relation ship between health promoting life style of studied students and their sex at Assuit University (2014).

\begin{tabular}{|l|c|c|c|}
\hline \multirow{2}{*}{\multicolumn{1}{|c|}{ Items Of HPL }} & \multicolumn{2}{c|}{ Sex } & \multirow{2}{*}{ P-value } \\
\cline { 2 - 4 } & Male & Female & \\
\cline { 2 - 4 } & Mean \pm SD & Mean \pm SD & \\
\hline Nutrition & $18.09 \pm 3.59$ & $15.74 \pm 3.39$ & $0.000^{*}$ \\
\hline Sports & $14.65 \pm 3.64$ & $11.35 \pm 3.49$ & $0.000^{*}$ \\
\hline Health & $28.16 \pm 7.09$ & $24.85 \pm 6.42$ & $0.000^{*}$ \\
\hline Stress-management & $21.60 \pm 3.85$ & $20.08 \pm 4.20$ & $0.004^{*}$ \\
\hline Inter-personal support & $22.44 \pm 4.09$ & $22.52 \pm 4.12$ & 0.882 \\
\hline Self-actualization & $42.37 \pm 6.64$ & $37.82 \pm 7.43$ & $0.000^{*}$ \\
\hline Total Health Promoting Lifestyles & $147.31 \pm 22.59$ & $132.36 \pm 21.37$ & $0.000^{*}$ \\
\hline
\end{tabular}

* There is statistical significance difference Independent samples $t$-test

Table (6): Relation ship between health promoting life style of studied students and their social class of studied students at Assuit university (2014).

\begin{tabular}{|l|c|c|c|c|}
\hline \multirow{2}{*}{\multicolumn{1}{|c|}{ Items Of HPL }} & \multicolumn{3}{c|}{ Social class } & \multirow{2}{*}{ P-value } \\
\cline { 2 - 5 } & Low & Middle & High & \\
\cline { 2 - 5 } & Mean \pm SD & Mean \pm SD & Mean \pm SD & \\
\hline Nutrition & $15.36 \pm 3.51$ & $16.03 \pm 3.35$ & $15.99 \pm 3.74$ & $0.050^{*}$ \\
\hline Sports & $11.30 \pm 3.41$ & $11.56 \pm 3.59$ & $11.91 \pm 3.80$ & 0.271 \\
\hline Health & $23.92 \pm 7.04$ & $25.18 \pm 6.32$ & $25.99 \pm 6.47$ & $0.007 *$ \\
\hline Stress-management & $19.81 \pm 4.31$ & $20.24 \pm 4.16$ & $20.40 \pm 4.20$ & 0.346 \\
\hline Inter-personal support & $22.47 \pm 4.07$ & $22.52 \pm 4.11$ & $22.52 \pm 4.22$ & 0.987 \\
\hline Self-actualization & $37.97 \pm 7.41$ & $38.14 \pm 7.40$ & $38.23 \pm 7.82$ & 0.937 \\
\hline Total Health Promoting Lifestyles & $130.83 \pm 22.00$ & $133.66 \pm 21.28$ & $135.05 \pm 23.21$ & 0.145 \\
\hline
\end{tabular}

* There is statistical significance difference ANOVA test

Table (7): Relation ship between health promoting life style of studied students and their qualification at Assuit University (2014).

\begin{tabular}{|l|c|c|c|c|}
\hline \multirow{2}{*}{\multicolumn{1}{|c|}{ Items Of HPL }} & \multicolumn{3}{|c|}{ Qualification } & \multirow{2}{*}{ P-value } \\
\cline { 2 - 5 } & $\begin{array}{c}\text { Faculty of } \\
\text { Nursing }\end{array}$ & $\begin{array}{c}\text { Institute of } \\
\text { Nursing }\end{array}$ & School of Nursing & \\
\cline { 2 - 5 } & Mean \pm SD & Mean \pm SD & Mean \pm SD & \\
\hline Nutrition & $15.58 \pm 3.61$ & $16.02 \pm 3.06$ & $16.21 \pm 3.59$ & $0.039^{*}$ \\
\hline Sports & $11.01 \pm 3.53$ & $12.61 \pm 3.07$ & $11.22 \pm 3.97$ & $0.000^{*}$ \\
\hline Health & $24.03 \pm 6.54$ & $25.98 \pm 6.05$ & $25.58 \pm 6.77$ & $0.000^{*}$ \\
\hline Stress-management & $19.90 \pm 4.25$ & $20.43 \pm 3.87$ & $20.31 \pm 4.45$ & 0.185 \\
\hline Inter-personal support & $22.18 \pm 4.29$ & $22.83 \pm 3.74$ & $22.66 \pm 4.24$ & 0.076 \\
\hline Self-actualization & $37.16 \pm 7.61$ & $38.71 \pm 6.72$ & $38.89 \pm 7.89$ & $0.002^{*}$ \\
\hline Health Promoting Lifestyles & $129.85 \pm 21.53$ & $136.58 \pm 19.38$ & $134.87 \pm 23.82$ & $0.000^{*}$ \\
\hline
\end{tabular}

* There is statistical significance difference ANOVA test 


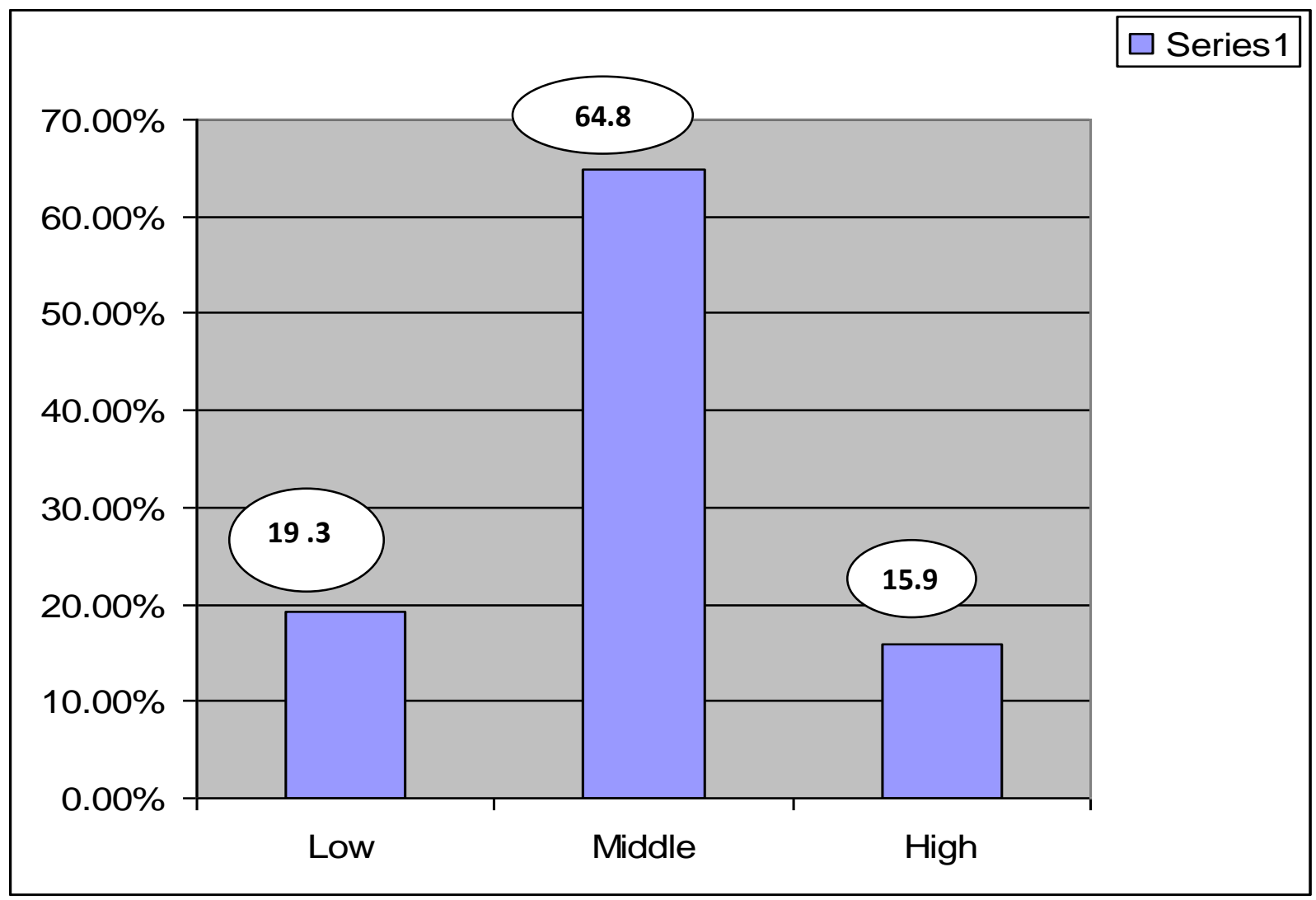

Figure (1): Distribution of the studied students according to social class at Assuit University,2014(n= 1045)

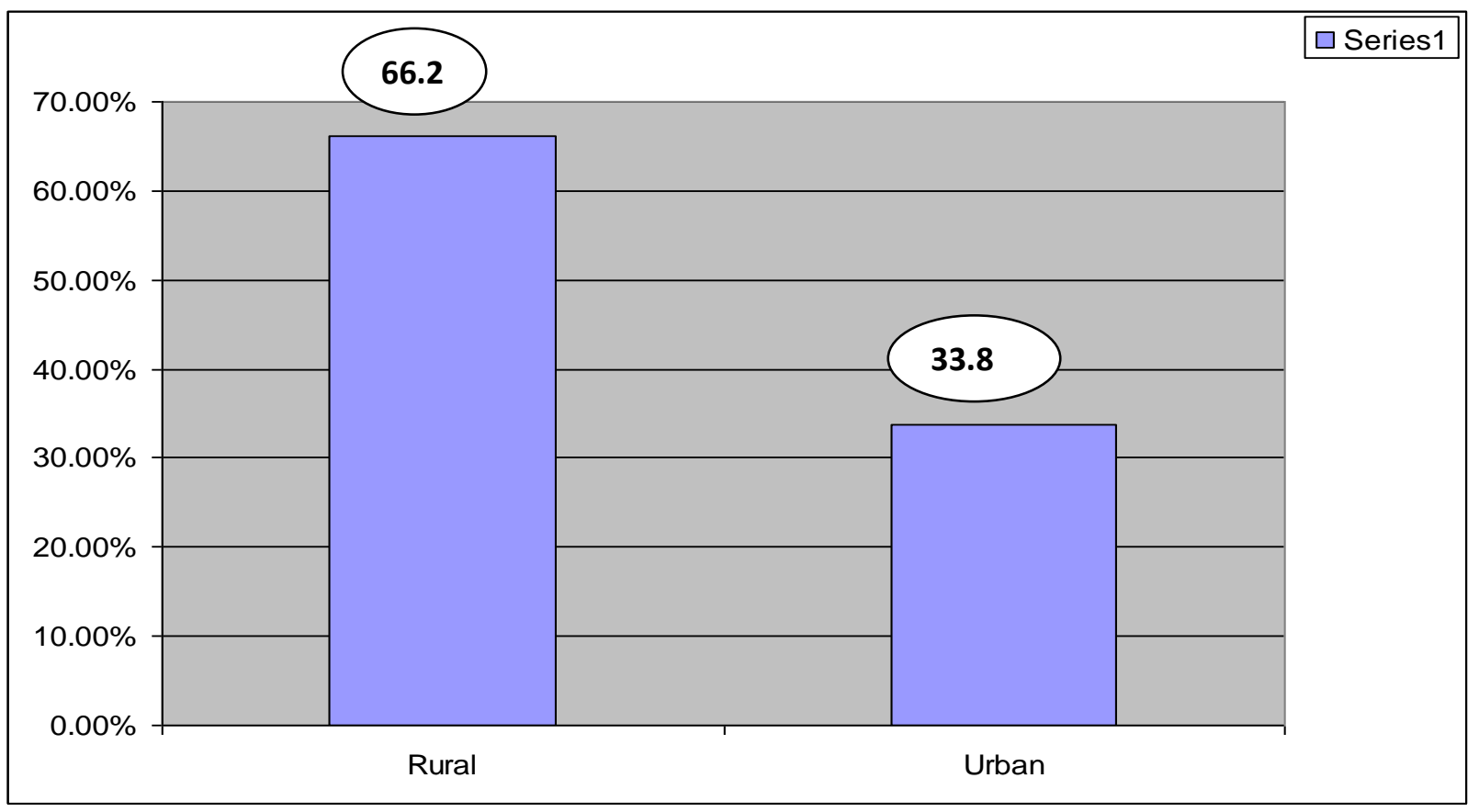

Figure (2): Distribution of the studied students according to residence at Assuit University, 2014(n= 1045). 
Table (1): Illustrates that $39.1 \%$ of the studied students were their age more than 17- years. Regarding to sex, $93.5 \%$ of the studied students were female while only $6.5 \%$ of them were male. $36.7 \%$ of students' mothers were illiterate while $32.1 \%$ of students' fathers had secondary school. $41.1 \%$ of the studied students were study in faculty of nursing while $27.9 \%$ were study in school of nursing. Regarding to BMI, it was noticed that $66.1 \%$ of the studied students were normal weight while only $8.6 \%$ and $5.1 \%$ of them were under weight and obese respectively.

Table (2): shows that the score of health promoting life style among studied students, it was noticed that mean score is higher in self-actualization and health $(38.12 \pm 7.46$ and $25.07 \pm 6.51)$ respectively.

Table (3): Shows that there is a statistical significant negative correlation between ages of studied students and health promoting life style domain and total HPL.

Table (4): Illustrated that the mean score HPL was higher in age group 15- years regarding nutrition stress-management, self-actualization and total HPL $(16.40 \pm 3.69,20.65 \pm 4.45,39.52 \pm 7.75$ and 136.80 $\pm 24.04)$ respectively .with a statistical significant difference $\mathrm{P}<0.001$.

Table (5): Show that the mean score was higher in male than in female regarding nutrition, sports, health, stress-management, self-actualization and total HPL with statistical significant difference $\mathrm{P}<$ 0.001 .

Table (6): Show that there is a statistical significant difference between Social class with nutrition and health in which $\mathrm{p}$ value $\left(0.050^{*}, 0.007 *\right)$ respectively.

Table (7): Show that there is a statistical significant difference between qualification of studied students with domains of HPL and total HPL (nutrition, sports, health and self-actualization) with $\mathrm{p}<0.05$.

Figure (1): revealed that the level of social class only $(15.9 \%)$ of studied students were high class while $(64.8 \%)$ of them were middle class.

Figure (2): Illustrated that In relation to students residence, about two thirds $(66.2 \%)$ of them were from rural area while $(33.8 \%)$ of them from urban area.

\section{Discussion}

The present study showed that, more than one third of the studied students were their age more than 17years Also, these findings may be attributed to the fact of normal ranking of the years of study in Egypt; 6-11 years for basic education followed by 3 years for preparatory education and 3 years secondary education then high education.
Ramadan \& Ahmed, (2015) supported the present findings that carried study about the effect of health educational program on depression, anxiety and stress among Female Nursing Students at Benha University reported that more than half of the intervention and control groups $64.0 \%$ \& $60.0 \%$ respectively were in age 19 years. The current study agree with Abbasi et al., (2014) who study nursing students' spiritual well-being, spirituality and spiritual care reported that the majority (93.2\%) of studied students ranged from 18 to 21 years.

Regard to the present study findings were consistent with El-houfey, (2010) who study students' health and wellness at Assuit University reported the range of university student's age was 17- 25 years. Also agree with Omedi et al, (2013) who study relationship between health promoting life style and life quality among nursing students found that most frequency was about 19-22 age group (59\%).

Concerning the present study showed that the vast majority of the studied students were females while only $(6.5 \%)$ of them were males, may be attributed to recent reception of males in high education of nursing. Also Omar, (2014) who study health promoting lifestyles of Jordanian university students reported that more than two thirds $(66.5 \%)$ of the studied students were females while $(33.5 \%)$ of them were males. Moreover Nassar \& Shaheen, (2014) who study health-promoting behaviors of university Nursing Students in Jordan Health found that females' students compromised 76\%, while males' students compromised $24 \%$ of the study sample.

Regarding to the health promoting lifestyle the present study shows that the mean score of student's is higher in self actualization and mean score was at least in sport $(38.12 \pm 7.46$ and $25.07 \pm 6.51)$ respectively. May be explained by associated with the culture and belief system of the Egyptian community and students not exercising because heavy study load at their university which take more time and energy In addition, the prevalence of computers and the internet services may reduce interest in sport and exercise activities and provide other alternatives of entertainment for the students. Sport equipments and facilities could be considered as the other reason which anticipates lack of participation in sport activities.

This result agree with Geok et al., (2014) who study physical activity and health-promoting lifestyle of student nurses in Malaysia reported that the highest score was reported in self actualization, with a mean score of $2.92 \pm 0.43$ while, physical activity was observed to be the lowest. Also agree with Nassar \& Shaheen, (2014) who reported that the highest mean in the life style subscales was $(25.04 \pm 4.70)$ for 
spiritual growth but the lowest was $(16.27 \pm 5.21)$ for physical activity.

Also agree with Golmakani et al., (2013) who study health promoting life style and its related factors in adolescent girls the highest mean score of life style subscales was allocated to the self actualization $(77.66 \pm 15.56)$ and the least to the physical and sport activities (51.66 \pm 22.49$)$.In the same line Omar, (2014) who found the highest mean score was for self actualization subscale $(\mathrm{M}=3.0, \mathrm{SD}=0.7)$ and the lowest mean score was for physical activity subscale $(\mathrm{M}=2.0, \mathrm{SD}=0.7)$.

This result also similar to Motlagh et al, (2011) who found that the highest score was related to self actualization and interpersonal communication. Interpersonal communication which provides social support and intimacy is considered as definite index of health status.

Moreover Hacıhasanoglu et al, (2011) who study healthy lifestyle behavior in university students and influential factors in eastern Turkey reported that highest mean score was for self actualization and the lowest mean score was for physical activity subscale. Also this result agree with Wei et al, (2012) who study assessment of health-promoting lifestyle profile in Japanese university students, Environmental Health and Preventive Medicine found that highest mean score was for self actualization and the lowest mean score was for physical activity subscale.

Also Bryer et al., (2013) who study healthpromotion behaviors of undergraduate nursing students, A Survey Analysis reported that highest mean score was for self actualization and the lowest mean score was for physical activity subscale. The third score in the present study was related to stress management $(20.18 \pm 4.20)$ and the results of the study were consistent with the studies of Wang et al, (2009) and Ortabag et al., (2011).

While in the studies of Tol et al., (2011) \& Motlagh et al., (2011) who reported that stress management ranked as fourth and fifth, respectively. This may be attributed to the students' academic life which is associated with greater stress and require more independent decision-making by the students. To achieve personal growth and the required perseverance needed to oppose life stress and to create healthy interpersonal relationships, they will commonly encounter several challenges, due to its priorities for the study group.

In the present study it was indicated that the mean score of health promoting life style was higher in male than in female regarding nutrition, sports, health, stress-management, self-actualization and total HPL with statistical significant difference $(\mathrm{P}<$ 0.001 ). it may be explained by the behavioral as well as socio cultural factors as females have fewer opportunities to go out side campus environment where as males can be more independent ,mobile and share exercise with their peers.

At the same time the finding agree with Omar, (2014) who study health promoting lifestyles of Jordanian university students found that the male students scored higher $(\mathrm{M}=2.5, \mathrm{SD}=0.5)$ than the female students $(M=2.4, S D=0.4)$ in their overall health-promoting lifestyle. Also Musavian et al, (2014) who reported that the health promotion mean score of male students was significantly higher than the mean score of female students $(P=0.003)$ and male students' mean scores of the nutrition, life appreciation, and physical activity dimensions were higher than the female students' mean scores $(\mathrm{P}<$ $0.05)$.

In contrast with Hosseini et al., (2015) who reported that mean of female students in subscales of nutrition, interpersonal relationship, health responsibility, spiritual growth, stress management, and total scale of health-promoting lifestyle profile 2 was higher than male students. In subscale of physical activity, the mean of male students was higher than females.

The current study disagreed with Suraj \& Singh, (2011) who Study sense of coherence health promoting behaviors in north Indian students and reported that the mean of Health promoting lifestyles were higher in female than male except physical activity. Also the current study disagree with Leung et al ,(2014) who carried study about the healthy lifestyles of enrolled nurse students of two nursing schools in Hong Kong reported that the mean HPLP were higher in female than male except physical activity.

\section{Conclusion}

The mean score of health promoting life style among studied students is higher in self-actualization and health $(38.12 \pm 7.46$ and $25.07 \pm 6.51)$ respectively .

\section{Recommendation}

- Increasing Health education programs for students about how to maintain health promote and achieve maximum level of well-being and avoid risky behaviors through pamphlets and posters.

- Increase further research about healthful life style and how to improve QOL for nursing students and other colleges in university.

- Increase student's awareness about the importance of periodic screening tests to detect high risk students for $\mathrm{HBV}, \mathrm{HCV}$ and other infectious diseases. 


\section{References}

1. Abbasi M., Farahani M., Mehrdad N., Givari A., \& Haghani H., (2014): Nursing students' spiritual well-being, spirituality and spiritual care Iran J Nurs Midwifery Res. 19(3): 242-247.

2. Abd El-twab, (2004): Socioeconomic scale, Faculty of education, Assiut University.

3. Ali H., Ameen D., Abd Elshakour S., \& AbdELA ZIZ M., (2012): Effect of a counseling program for diabetic patients on their knowledge, health promoting lifestyle practices, and psychological status Journal of American Science, $\quad 8(10)$ : 510-518. http://www.jofamericanscience.org.

4. Bryer J., Cherkis F., \& Raman J., (2013): Health-promotion behaviors of undergraduate nursing students: a survey analysis. Nursing Education Perspectives, 34:410-415. http://dx.doi.org/10.5480/11-614

5. El-Houfey A., (2010): Students health and wellness at Assuit university Thesis Submitted for Partial Fulfillment of the Doctor's Degree in Community Health Nursing, pp 15-25.

6. Geok S., Yusof A., Lam S., Japar S ., Leong O., Sofian M., \& Fauzee O., (2014): Physical Activity and Health-Promoting Lifestyle of Student Nurses in Malaysia, Journal of Biosciences and Medicines,3:7887http://www.scirp.org/journal/jbm http://dx.doi.org/10.4236/jbm.2015.33012

7. Golmakani N., Naghibi F., Moharari F., \& Esmaily H., (2013): Health Promoting Life style and its Related Factors in Adolescent Girls Journal of Midwifery and Reproductive Health, 2013; 1(1):42-49.

8. Hachhasanoglu R., Yıldırım A., Karakurt P., \& Saglam R., (2011): Healthy lifestyle behavior in university students and influential factors in eastern Turkey, International Journal of Nursing Practice, 17: 43-51. http://dx.doi.org/10.1111/j.1440172X.2010.01905.x.

9. Hosseini M., Ashktorab T., Taghdisi M., Vardanjani A., \& Rafiei H., (2015):HealthPromoting Behaviors and Their Association With Certain Demographic Characteristics of Nursing Students of Tehran City Global Journal of Health Science; 7(2): 264. http://dx.doi.org/10.5539/gjhs

10. Lawan U., Wali N., \& Musa A., (2010): Menstruation and Menstrual Hygiene amongst Adolescent School Girls in Kano, Northwestern Nigeria, African Journal of Reproductive Health, 14(3): 201.
11. Leung L., Andrew F., Wai W., Stephanie S., (2014): The healthy lifestyles of enrolled nurse students of two nursing schools in hong kong, Macau journal of nursing ,13(1): 30-35.

12. Motlagh Z., Mazloomy S., Momayyezi M., (2011): Study of Health-promotion behaviors among university of medical science students. Zahedan Journal of Research in Medical Sciences 13(4): 29-34.

13. Musavian A., Pasha A., Rahebi S., Roushan Z., \& Ghanbari A., (2014): Health promoting Behaviors Among Adolescents, A Crosssectional Study, Nursing Midwifery Study Journal, 3(1): 4560.

14. Nassar O., \& Shaheen A., (2014): HealthPromoting Behaviors of University Nursing Students in Jordan Health, 6: 2756-2763 Published Online November 2014 in Sci Res. http://www.scirp.org/journal/health.

15. Omar A., (2014): health promoting lifestyles of Jordanian university students international journal of advanced nursing studies 3(1) 27-31.

16. Omedi K., Ajdari Z., \& Arbabisarjou A., (2013): Relationship between health promotion life style and life quality among nursing students, World of Sciences Journal, (02): 140-147.

17. Ortabag T., Ozdemir S., Bakir B., \& Tosun N., (2011) Health Promotion and Risk Behaviors Among Adolescents in Turkey, The Journal of School Nursing, ;27(4):304-15.

18. Pender N., (1996). Health promotion in nursing practice (3rd ed.). Stamford, CT: Appleton and Lange.

19. Ramadan E., \& Ahmed H., (2015): The Effect of Health Educational Program on Depression, Anxiety and Stress among Female Nursing Students at Benha University, IOSR Journal of Nursing and Health Science (IOSR-JNHS) 4(3): 49-56.

20. Suraj S., \& Singh A., (2011): Study of sense of coherence health promoting behavior in north Indian students Indian J Med Res 134: 645-652.

21. Tol A., Tavassoli E., Shariferad G., \& Shojaezadeh D., (2011): The relation between health-promoting lifestyle and quality of life in undergraduate students at school of health, Isfahan University of Medical Sciences, Journal Health System. 7(4):442-448. Persian.

22. Wang D., Quen C., Chen M., \& Duan N,(2009): Health-promoting lifestyles of university students in Mainland China. Bio Med Central Public Health, 9(1):379. Doi: 10.1186/1471-2458-9-379. 
23. Wei C., Harada K., Ueda K., Fukumoto K., Minamoto K., \& Ueda A., (2012): Assessment of health-promoting lifestyle profile in Japanese university students, Environmental Health and Preventive Medicine, 17: 222-227, http://dx.doi.org/10.1007/s12199-011-0244-8

24. Wittayapun Y., Tanasirirug V., Butsripoom B., \& Ekpanyaskul C., (2013): Factors Affecting Health-promoting Behaviors in Nursing Students of the Faculty of Nursing and Srinakharinwirot University, Thailand J ournal of Public Health, 40:215-225.

25. World Health Organization, (2009): The European Health Report 2009: Health and Health Systems. Available from http://www.euro.who.int/data/assets/pdf_file/000 9/82386/E93103.pdf . 